\title{
PERANCANGAN ALAT PENGERUK GARAM MENGGUNAKAN SISTEM BLADE DOZER DAN CONVEYOR
}

\author{
Laily Uliyah ${ }^{1}$, Dika Rama², Amin Jakfar ${ }^{3}$ \\ 1,2,3 Teknik Mesin Alat Berat, Politeknik Negeri Madura \\ Jalan Raya Taddan Km.4, Camplong, Sampang, Madura \\ lailyulfiyah0608@gmail.com ${ }^{1}$
}

\begin{abstract}
Abstrak
Pulau Madura merupakan salah satu penyokong kebutuhan garam nasional, dan proses panen garam masih dilakukan secara tradisional. Hal ini menyebabkan produksi garam masih kurang untuk memenuhi kebutuhan garam nasional. Untuk itu dibutuhkan alat yang mampu membantu produksi garam. Perancangan dan pembuatan alat pengeruk garam untuk membantu proses panen garam merupakan salah satu cara mengatasi hal ini. Alat pengeruk garam ini dirancang dengan memanfaatkan fungsi blade yang bergerigi pada dozer untuk memecah dan mengeruk garam, serta memafaatkan fungsi conveyor yang digerakkan dengan mesin Honda Astrea Grand 100cc untuk membantu garam masuk ke penampung. Pada alat ini juga dilengkapi karung penampung kapasitas $25 \mathrm{Kg}$, sehingga garam bisa langsung diangkut dari lahan ke tempat penampungan akhir untuk dijemur. Material rangka yang dipakai adalah pipa besi diameter 2inch sebagai pegangan kendali alat, plat besi galvanis $2 \mathrm{~mm}$ sebagai bahan conveyor dan besi hollow dipakai sebagai rangka. Sistem kerja alat ini, yaitu mengeruk, menampung dan garam bisa langsung diangkut ke tempat penampungan . Alat ini mampu mempercepat proses panen garam sebesar 100\% daripada dengan menggunakan pengeruk manual sekaligus menghemat tenaga petani garam.
\end{abstract}

Kata kunci: garam, blade, conveyor, pengeruk

\begin{abstract}
Madura Island is one of the supporters of the national need for salt, and the salt harvesting process is still carried out traditionally. This causes salt production to be insufficient to meet national salt needs. For that we need a tool that can help salt production. The design and manufacture of a salt scraper to assist the salt harvesting process is one way of dealing with this. This salt scraper is designed to take advantage of the function of the serrated blade on the dozer to break and dredge the salt, as well as to take advantage of the conveyor function which is driven by the Honda Astrea Grand 100cc engine to help the salt enter the container. This tool is also equipped with a storage sack with a capacity of $25 \mathrm{~kg}$, so that the salt can be directly transported from the land to the final storage area for drying. The frame material used is a 2 inch diameter iron pipe as a tool control handle, 2 mm galvanized iron plate as a conveyor material and hollow iron is used as a frame. The working system of this tool, namely dredging, storing and the salt can be directly transported to the shelter. This tool is able to speed up the salt harvesting process by 100\% compared to using a manual scraper while saving the labor of salt farmers.
\end{abstract}

Keywords : salt, blade, conveyor, dredge

\section{PENDAHULUAN}

Komoditas garam, selain untuk memenuhi kebutuhan konsumsi juga digunakan untuk memenuhi kebutuhan industri. Tercatat kebutuhan garam nasional pada 2015 untuk konsumsi dan industri sebesar 3,8 juta ton yang terdiri atas 1,7 juta ton untuk keperluan konsumsi dan 2,1 juta ton untuk keperluan industri. Produksi garam nasional yang dilakukan oleh petani garam dan PT. Garam sebagai satu-satunya BUMN yang memproduksi garam hanya sebesar 2,1 juta ton. Pemenuhan kekurangan garam sebesar 1,7 juta ton dipenuhi dari impor. Kondisi ini menunjukkan suatu ironi dimana Indonesia merupakan negara yang kaya akan potensi sumberdaya laut namun belum mampu memenuhi kebutuhan garam nasional. Hal itulah yang menyebabkan Indonesia mengimpor garam dengan nilai Rp lebih dari 1 triliun ( 90,000 USD) setiap tahunnya [1]. 
Produksi garam yang diterapkan masyarakat Madura pada umumnya masih bersifat tradisional, seperti pada Gambar 1 dan Gambar 2, berupa pengeruk dari kayu dengan menggunakan tenaga manusia sehingga membutuhkan waktu pengkerjaan yang cukup lama dan perlu tenaga pengeruk yang banyak. Sehingga produksi garam masih belum bisa maksimal, karena peralatan dalam proses panen garam masih konvensional. Untuk itu dibutuhkan alat yang dapat membantu proses panen sehingga produksi meningkat. [2]

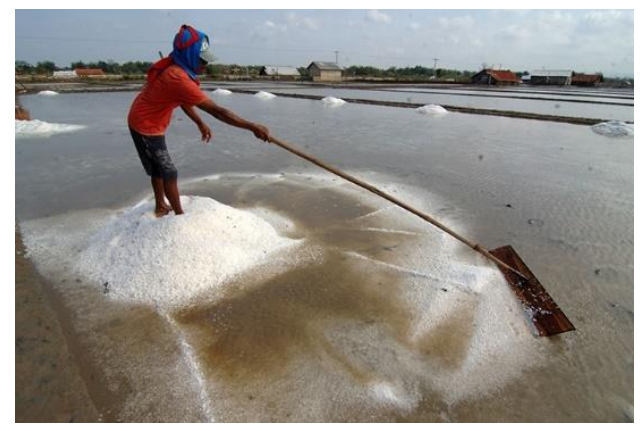

\section{Gambar 1 Proses Panen Garam dengan} Pengeruk Manual [3]

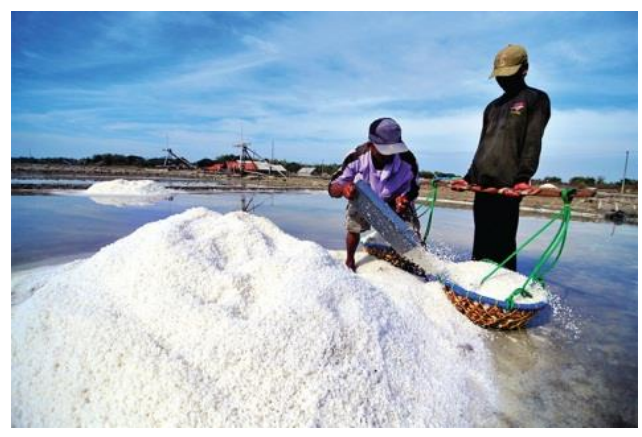

Gambar 2 Pengankutan Garam Hasil Keruk [3]

Perancangan alat pengeruk yang dapat membantu proses pengerukan garam ini dirancang dengan sistem blade dan conveyor yang merupakan hasil modifikasi dari alat yang ada sebelumnya di pasar. Dengan konsep desain, yaitu penambahan komponen blade dan conveyor serta perubahan dimensi menyesuaikan kondisi beban.

Penggunaan sistem pengerukan pada dozer akan dipakai sebagai alat pengeruk pada alat pengeruk garam yang akan dirancang. Pengeruk menggunakan sistem blade pada dozer, yaitu universal blade ( $U$ blade) yang dilengkapi dengan sayap (wing) yang terdapat di sisi blade kegunaanya untuk efektifitas produksi. Pada dozer blade ini memungkinkan dozer membawa/mendorong muatan lebih banyak, umumnya bulldozer dengan jenis ini digunakan untuk pekerjaan reklamasi tanah (land reclamation) [4].

Berdasarkan Gambar 3 pada kenyataanya alat pengeruk yang sudah ada dipasaran hanya untuk pengerukan tidak disertai dengan penambahan sistem penumpahan ke karung garam berupa conveyor.

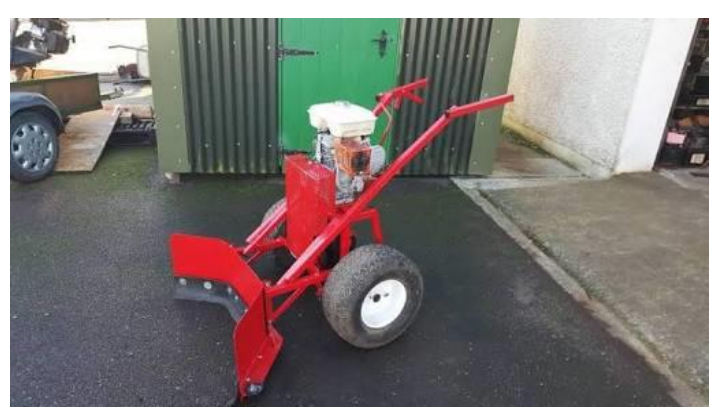

Gambar 3 Alat Pengeruk di Pasaran [5]

\section{METODE}

\section{Diagram Alir Perancangan Pembuatan Alat}

Proses perancangan pembuatan alat dalam bentuk diagram alir pada Gambar 4. Berdasarkan Gambar 4 alat dan bahan yang digunakan adalah:

1. Plat besi

2. Pipa besi

3. Besi Hollow

4. Mesin Honda astrea 100cc untuk penggerak conveyor

5. Sprocket

6. Roda ban $1480 / 90$

7. Tuas dan kabel rem

8. Rantai

9. Drum brake set

10. Velg R14

11. Mesin las

12. Peralatan bengkel

13. As roda

\section{Desain Alat}

Desain alat pengeruk ini pada Gambar 5. Keterangan Alat:

1.Conveyor

2.Pegangan sebagai kontrol gerakan alat

3.Roda R14 ban 15 80/90

4.Mesin penggerak conveyor Gasoline engine, daya 5,5 HP atau $3600 \mathrm{rpm}$

5.Blade 


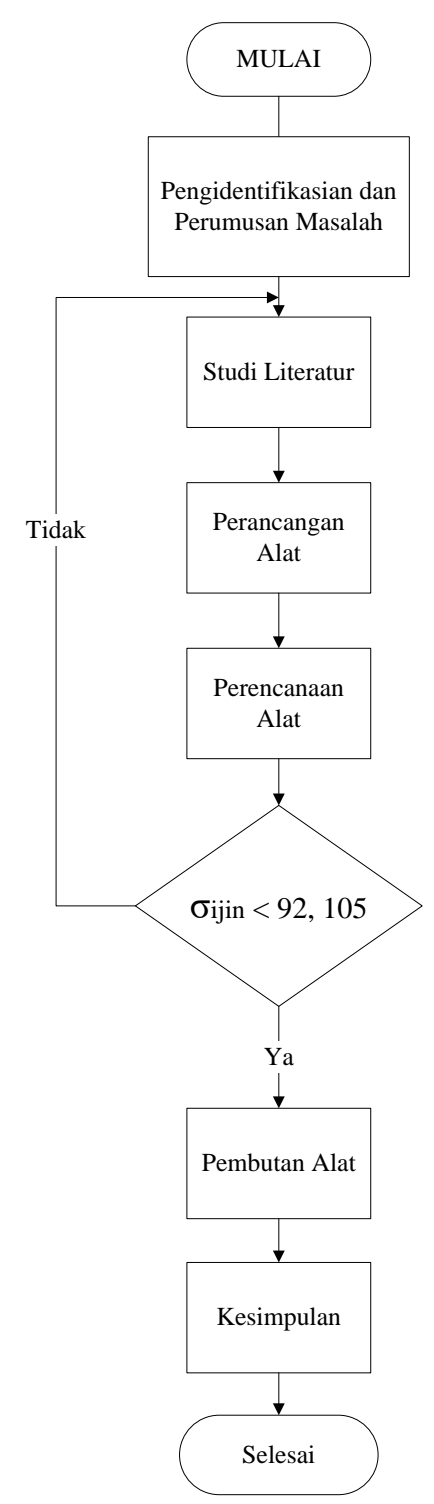

Gambar 4 Diagram Alir Perencanaan

\section{Prinsip Kerja Alat}

Prinsip kerja alat pengeruk garam, yaitu mesin memutar sprocket, kemudian putaran sprocket diteruskan rantai ke bagian sproket penggerak conveyor. setelah mesin menyala conveyor ikut menyala, lalu roda bergerak maju blade akan mengeruk garam kearah depan dan digunakan untuk menggerakan conveyor agar dapat berputar menumpahkan garam tersebut ke wadah (karung penampung), sehingga garam yang terkeruk dapat langsung masuk ke wadah yang telah disediakan. Apabila garam diwadah sudah penuh wadah dapat diganti secara manual letika ditepi petak garam.

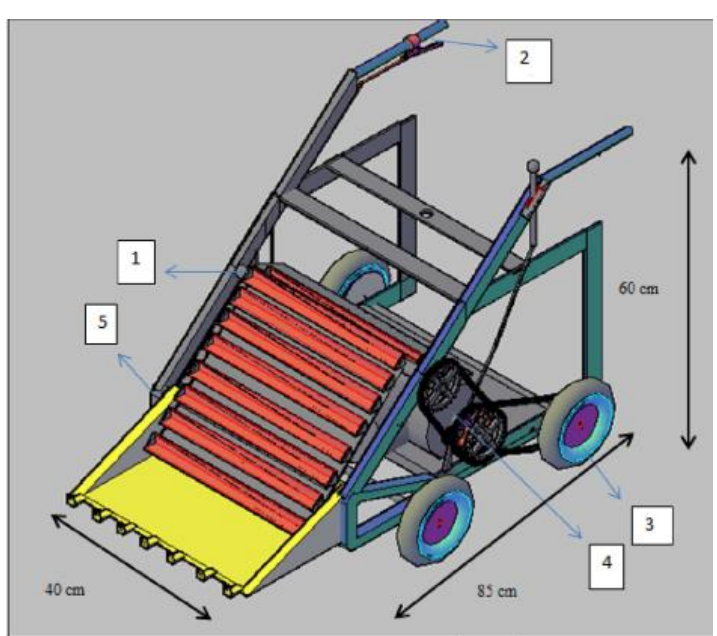

Gambar 5 Desain Alat Pengeruk

\section{HASIL DAN PEMBAHASAN}

\section{Perancangan}

1. Perancangan coveyor

- Penentuan Sudut Kemiringan Conveyor Untuk mengetahui sudut yang digunakan dapat dihitung menggunakan persamaan 1 [6]

$\tan \emptyset=\frac{\mathrm{L}}{\mathrm{P}}$

Maka sudut kemiringinan conveyor dengan penentuan lebar rangka $(L)=40 \mathrm{~cm}$ dan tinggi rangka $(\mathrm{P})=60 \mathrm{~cm}$,

$$
\begin{aligned}
& \tan \emptyset=\frac{40}{60} \\
& \tan \emptyset=\frac{40}{60} \\
& \tan \theta \quad=0,67 \\
& \theta \quad=33,8^{\circ}
\end{aligned}
$$

Sudut kemiringan conveyor $=33,8^{\circ}$

- Penentuan Panjang Conveyor

Panjang perancangan conveyor berdasarkan tinggi dan panjang rangka dapat dihitung menggunakan persamaan 2 [7] $c^{2}=a^{2}+b^{2}$

Maka panjang conveyor, adalah

$c^{2}=a^{2}+b^{2}$

$c^{2}=40^{2}+60^{2}$

$c^{2}=5200$

$c=\sqrt{5200}=72,1 \mathrm{~cm}$

- Penentuan Kecepatan

Kecepatan yang dibutuhkan untuk menyalurkan garam pada corong penampungan, dengan persamaan 3 [8] 
$\mathrm{v}=\mathrm{rpm}$ mesin $\mathrm{x}$ tinggi corong

maka,

$$
\begin{aligned}
v & =1800 \mathrm{rpm} \times 0,3 \mathrm{~m} \\
v & =540 \mathrm{~m} / \text { menit } \\
& =9 \mathrm{~m} / \text { detik }
\end{aligned}
$$

- Kecepatan yang dibutuhkan perbucket ke corong dengan persamaan 4, [9] $v=$ Rpm $x$ keliling pulley

Dengan

$$
\begin{aligned}
& \text { Keliling pulley }=0,3 \mathrm{~m} \\
& \mathrm{n} \quad=40 \mathrm{Rpm} \text { (asumsi) } \\
& \mathrm{v} \quad=40 \mathrm{Rpm} \times 0,3 \mathrm{~m} \\
& \quad=12 \text { meter } / \text { menit } \\
& \mathrm{v} \quad=0,2 \text { meter/detik }
\end{aligned}
$$

- Waktu berdasarkan panjang lintasan conveyor dengan persamaan 5 [10]

$$
t=\frac{\frac{\text { panjang lintasan conveyor }}{\text { jumlah bucket }} \mathrm{cm}}{\text { kecepatan perbucket }\left(\frac{\mathrm{m}}{\mathrm{s}}\right)}
$$

Dengan'

Panjang lintasan conveyor $=72,1 \mathrm{~cm}$

Jumlah bucket $=8$

Kecepatan per bucket $=0,2 \mathrm{~m} / \mathrm{s}$

Maka,

$t=\frac{\frac{72,1}{8} \mathrm{~cm}}{0,2\left(\frac{m}{\mathrm{~s}}\right)}$

$\mathrm{t}=45$ detik

Berarti waktu kecepatan yang dihasilkan untuk mengangkut garam $1 \mathrm{~kg}$ garam membutuhkan 0,45 detik.

\section{Perancangan Rangka}

\section{Tegangan Kerja}

Tegangan kerja pada kontruksi rangka dapat dihitung menggunakan persamaan 6 [11] $\mathrm{w}=\frac{\mathrm{M} . \mathrm{c}}{\mathrm{I}}$

$$
\begin{aligned}
& \text { Atau } \\
& \sigma m=\frac{\varepsilon f}{\mathrm{~A}}
\end{aligned}
$$

\section{Dengan:}

$$
\begin{array}{ll}
\mathrm{W} & =\text { Tegangan kerja }\left(\frac{\mathrm{N}}{\mathrm{m}}\right) \\
\mathrm{M} & =\text { Momen pada Rangka }(N . m) \\
\mathrm{I} & =\text { Inersia }(\mathrm{m}) \\
\mathrm{c} & =\text { Titik tengah profil material }(\mathrm{m})
\end{array}
$$

\begin{tabular}{|c|c|c|}
\hline $\mathrm{NO}$ & Safety factor & Kondisi \\
\hline 1 & $1,25-1,5$ & $\begin{array}{l}\text { Kondisi terkontrol dan tegangan } \\
\text { kerja dapat dipastikan }\end{array}$ \\
\hline 2 & $1,5-2$ & $\begin{array}{l}\text { Bahan sudah diketahui, kondisi } \\
\text { lingkungan beban dan beban yang } \\
\text { tetap dan dapat dengan mudah } \\
\text { ditentukan }\end{array}$ \\
\hline 3 & $2-2,5$ & $\begin{array}{l}\text { Benda beroperasi secara rata-rata } \\
\text { dengan batasan beban yang } \\
\text { diketahui }\end{array}$ \\
\hline 4 & $2,5-3$ & $\begin{array}{l}\text { Bahan diketahui tanpa melalui tes, } \\
\text { pada kondisi beban dan tegangan } \\
\text { rata-rat }\end{array}$ \\
\hline 5 & $3-4,5$ & $\begin{array}{l}\text { Bahan sudah diketahui, beban, } \\
\text { tegangan dan lingkungan yang tidak } \\
\text { pasti }\end{array}$ \\
\hline
\end{tabular}

maka,

tegangan kerja

$$
=\frac{\text { gaya wadah }+ \text { gayamesin }}{p \times l}
$$

tegangan kerja $=\frac{25 \mathrm{~kg}+20 \mathrm{~kg}}{60 \mathrm{~cm} x 40 \mathrm{~cm}}=0,01875 \mathrm{~kg} / \mathrm{cm}^{2}$

2. Tegangan Ijin

$$
\begin{aligned}
& \text { Tegangan ijin dengan persamaan } 7 \text { [12] } \\
& \sigma t=\frac{\sigma m}{\mathrm{sf}}
\end{aligned}
$$

Maka dengan nilai safety aktor seperti pada kondisi berikut sesuai dengan Tabel 1 nilai tegangan ijin untuk alat pengeruk ini adalah:

$$
\text { бijin }=\frac{0,01875 \mathrm{~kg} / \mathrm{cm}^{2}}{2}=0,009375 \mathrm{~kg} / \mathrm{cm}^{2}
$$

safety factor yang digunakan adalah 2

\section{Tabel 1 Nilai Safety Factor}

3. Spesifikasi Mesin

Berikut Tabel 2 menunjukan spesifikasi mesin yang akan digunakan

Tabel 2 Spesifikasi mesin

\begin{tabular}{ll}
\hline Kategori & Spesifikasi \\
\hline Tipe & $\begin{array}{l}\text { Air cooled 4 tak OHV } \\
\text { single Cylinder, } \\
\text { Horizontal Shaft }\end{array}$ \\
& $163 \mathrm{cc}$ \\
Volume silinder & $10,3 \mathrm{Nm} / 2500 \mathrm{rpm}$ \\
Torsi maksimum & $5,5 \mathrm{HP} / 3600 \mathrm{rpm}$ \\
Output maksimum & $3,1 \mathrm{liter}$ \\
Kapasitas tangka & 0,6 liter \\
Kapasitas oli & $312 \times 363$ × 335 mm \\
Dimensi & \\
\hline
\end{tabular}


Untuk menentukan putaran poros yang direduksi agar sesuai dengan kebutuhan tenaga untuk menggerakan alat menggunakan persamaan 8 [14].

$$
i=\frac{N 1}{N 2}=\frac{D 1}{D 2} \text {. }
$$

Maka,

$$
\begin{aligned}
i & =\frac{N 2}{N 1} \\
i & =\frac{2500 \mathrm{rpm}}{1000 \mathrm{rpm}} \\
i & =\frac{2,5}{1} \\
i & =\frac{D p}{d p}=\frac{2,5}{1}
\end{aligned}
$$

Jadi perbandingan Dp : dp adalah 2,5 : 1 maka untuk mendapatkan putaran poros $600 \mathrm{rpm}$ dapat digunakan pulley dengan diameter $20 \mathrm{~cm}$ dan 8 $\mathrm{cm}$. pulley tersebut digunakan untuk transmisi pada mesin yang akan dihubungkan ke mesin.

\section{Hasil Perancangan dan Pembuatan Alat}

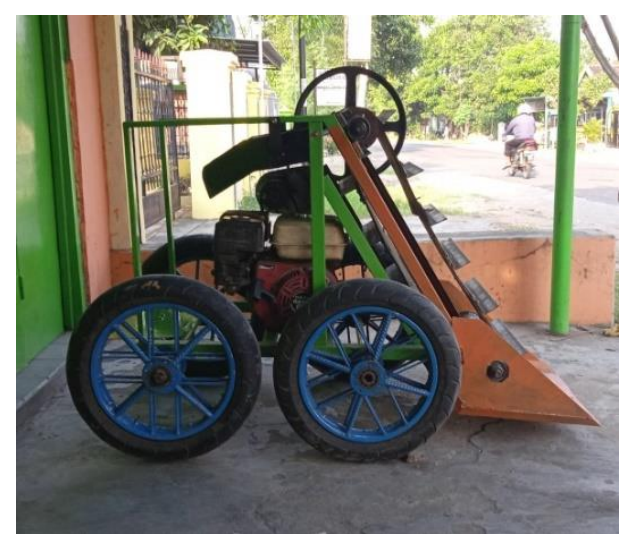

Gambar 5 Hasil Perancangan dan Pembuatan Alat

\section{Uji Coba dan Perbandingan}

Data hasil uji coba pada Tabel 3 dengan asumsi luas lahan $60 \mathrm{~m} 2$, yaitu $10 \times 6 \mathrm{~m}$, dengan ketebalan garam $\pm 2 \mathrm{~cm}$. Sedangkan karung penampung garam mempunyai kapasitas $25 \mathrm{Kg}$.

Tabel 3 Data Hasil Uji Coba

\begin{tabular}{llcl}
\hline NO & $\begin{array}{l}\text { Kg } \\
\text { garam }\end{array}$ & $\begin{array}{l}\text { Waktu } \\
\text { menggunakan } \\
\text { (menit) }\end{array}$ & $\begin{array}{l}\text { Waktu } \\
\text { produksi } \\
\text { manual (menit) }\end{array}$ \\
\hline 1 & $25 \mathrm{Kg}$ & 0,75 & 4.61 \\
\hline
\end{tabular}

\section{KESIMPULAN}

Berdasarkan data uji coba dapat disimpulkan bahwa untuk memanen garam dengan luas lahan $60 \mathrm{~m} 2$ membutuhkan waktu sekitar 36 menit, sedangkan untuk produksi manual membutuhkan waktu 221,8 menit atau 13,308 jam. Penggunaan blade dan conveyor mempercepat proses pengerukan.

\section{DAFTAR PUSTAKA}

[1] Ihsanudin, S. P. (2016). Strategi Pemberdayaan Ekonomi Petani Garam Melalui Pendayagunaan Aset Tanah Pegaraman. Economics Development Analysis Journal, 15.

[2] Safuan, Anwar. "Di Tengah Panceklik, Petani Garam Jepara Masih Tersenyum". Media Indonesia. 24 Juli 2019.

[3] Bahri, Saiful. Di Tengah Panceklik, Petani Garam Jepara Masih Tersenyum". Media Indonesia. 24 Juli 2019.

[4] Jumantoro, S. (2013). Mesin-Mesin Khusus Alat Berat Buldozer. Yogyakarta

[5] Dewa. "Alat Panen Garam dari Pati Dipesan Kementerian Desa" Suara Merdeka. 18 April 2018.

[6] Forbo Group. PT Forbo Siegling Indonesi. No ref 206.23. Bandung, Jawa Barat. .

[7] Mulyono, M.T., Hendrayati, Roro Heni. "Rancang Bangun Belt Conveyor untuk Penyaji Makanan". Pada Seminar Nasional Teknologi dan Rekayasa (SENTRA 2016), vol. IV. 2017.

[8] Sularso, K. S. (2004). Dasar Perancanaan dan Pemilihan Elemen Mesin. Jakarta:

[9] Cahyadi, Dadi., Azis, Gilang Febri. "Perancangan Belt Conveyor Kapasitas 30 Ton/Jam Untuk Alat Angkut Kertas". Pada SINTEK Vol 9 No. 1.

[10]Daryanto, D. (2012). Dasar-Dasar Teknik Mesin. Jakarta: PT. Rineka Cipta

[11]Warren C. Young, R. G. (2002). Roark's Formulas for Stress and Strain. New york : the McGraw-Hill.

[12]Gupta, R. K. (2005). A TEXTBOOK OF Machine Design. Ram Nagar, New Delhi: Eurasia Publishing House (PVD.) LTD.

[13] Sofyan, B. t. (2010). Pengantar Material Teknik. Jakarta: Salemba Teknika.

[14]Pongsapan, L. (2016). Pengaruh Pembebanan Overload Bucket Terhadap Kekuatan Material Komponen Arm Pada Excavator Volvo EC700B Tipe Crawler. Transmisi.

[15] Priambodo, A. B. (1982). ELEMEN MESIN. JAKARTA: ERLANGGA 